\title{
Use of GIS to Estimate Productivity of Eucalyptus Plantations: A Case in the Biobio Chile's Region
}

\author{
Rolando Rodríguez and Pedro Real
}

Additional information is available at the end of the chapter

http://dx.doi.org/10.5772/47949

\section{Introduction}

In the past, today and the future, forest productivity has become an important issue to ensure the sustainability of forest resources. In a modern sense of concept, forest sustainability may be defined as the combination of biological (biotic), environmental (abiotic), and cultural factors that determine the rate at which the forest overcomes "environmental resistance" and achieves the potential productivity of a site (Medlyn et al., 2011).

Governments and managers need to ensure that society is provided with forest products in both ecologically and economically correct ways, considering social aspects. Therefore, forest productivity is an important criterion of sustainability because of its strong relationship with economics and profitability.

Managers are insistently demanding precise estimates of forest biomass productivity and potential growth rates at global and local scales. This situation creates the necessity of research in growth and yield simulation, since accurate prediction is decisive for decisionmaking. The quality of decision is strongly influenced by the types of models. Innovative simulation strategies are essential to predict potential impacts of future changes in the global environment (Medlyn et al., 2011).

On the one side, classical growth and yield forest models have been criticized as being empirical, with models revealing little about physiological mechanisms that control the adaptation to environmental conditions. On the other side, complex mechanistic models of growth have been criticized as being cumbersome, requiring too many hard to measure inputs variables and relying heavily on untested assumptions (Pinjuv, 2006). The above considerations lead to the conclusion that the best option is to combine both types: empirical and process-based models in a joint and calibrated hybrid model (Almeida, et al., 2004). 
Rather than using empirical measurements or complex mechanistic models of growth, process-based modeling attempts to simulate the general ecological mechanism of a given ecosystem. Within the advances in computing technologies and understanding of ecological process, process-based simulations models are providing means to address scientific and management questions at all spatial scales, from individual trees to the entire globe (Kirk \& Burk, 2004).

Forest managers are interested not only in the characteristics of specific trees or forest stands, but also in trends that extend across large areas such as watershed, landscapes or ecoregions (Shindler, 1998). While scientifically based management at these coarse scales is desired, collecting appropriate data is a major challenge. Process-based models provide a viable alternative to large-scale field sampling for several reasons (Kirk \& Burk, 2004).

This paper discusses a generalized framework for developing a regional-scale process-based forest productivity model implemented for the study of the environmental limitations on the growth of Eucalyptus nitens plantations. Maps of potential productivity are developed and regulations of productivity by environmental factors are discussed. Additionally, comments are added on the usefulness of GIS in the study of spatial patterns that govern forest productivity.

\section{Modeling forest system}

\subsection{Empirical model}

Forests are very complex ecosystems, and historically many approaches to predict yield and productivity of forests sites have been developed. Growth and yield of forest sites have been modeled in different ways, and different productivity measures exist as site index, site quality and potential site (Daniel et al., 1979).

Vanclay (1994) has defined stand growth model as "an abstraction of the natural dynamics of a forest stand, which may encompass growth, mortality, and other changes in stand composition and structure". Common usage of the term "growth model" generally refers to a system of equations which can predict the growth and yield of a forest stand under a wide variety of conditions. Thus, a growth model may comprise a series of mathematical equations, the numerical values embedded in those equations, the logic necessary to link these equations in a meaningful way, and the computer code required to implement the model on a computer. In its broadest sense, the term may also embrace yield tables and curves, which are analogous to equations, but which have been stated in a tabular or graphical form, rather than a mathematical form (Vanclay, 1994).

An important but simple model in forestry is the plantation yield table, which may comprise only of two columns of figures: age and the expected standing volume at that age. The yield table may also be expressed graphically as a series of curves, with the horizontal axis indicating age and the vertical axis indicating volume produced. It may also be expressed more concisely as a mathematical equation (Vanclay, 1994). 
In Chile, empirical growth and yield simulators have been developed to be used in intensively managed plantations of Pinus radiata, Eucalyptus globulus and Eucalyptus nitens. To improve its predictive ability, the Chilean model has been adapted to growth zones and, stratification is used to improve the productivity measure (Site Index) of the simulator. In Chile, the need to incorporate physiographic, soil and climate data as continuous covariables instead of zones is relevant. However, the weakness of the discrete territory handling that is implicit in the modeling strategy has become evident over time.

In general, limitations of the approach taken are: 1) predictions are based on historical data records, 2) lack of necessary flexibility to estimate changes in the stand growth in response to environmental changes, 3) limited capabilities of extrapolation when new treatments are not considered in the fitting data base, and finally, 4) the development and maintenance of plot networks are expensive to establish and re-measured (Bernier et al., 2003).

Empirical models are used in most forest companies and remain valuable tools for management, but they do not provide answers to some critical questions that arise in the planning process, especially those related to factors that are affected by silviculture and climate (Constable \& Friend, 2000). However, recent approaches tend to improve the applicability of empirical models under changing conditions. Examples of these approaches are 1) the dynamic state-space approach, or 2) the development of productivityenvironments relationship (Fontes et al., 2010).

\subsection{Process-based model}

Limitations described for empirical models, have led to the exploration of new and more consistent productivity definitions, such as concepts and methods used by ecologists, of which the most common productivity measurements are gross primary productivity (GPP), net primary productivity (NPP) and net ecosystem productivity (NEP). Growth can be defined as the net accumulation of carbon and other organic materials in plants. An indirect measurement of growth is used for the photosynthetic and respiration rates (Hari et al., 1991).

The processes governing forest growth are well-recognized and understood (Landsberg, 1986; Landsberg \& Gower, 1997). Photosynthesis, driven by radiant energy intercepted by the foliage, produces carbohydrates, which are respired to provide the energy needed for protein synthesis and formation of new tissues, and partitioned to branches and stems, coarse and fine roots and new foliage (Landsberg \& Waring, 1997). Photosynthetic efficiency is affected by the nutrient status of the foliage, and also depends on the uptake of $\mathrm{CO}_{2}$ through stomata, which may be affected by the water status of the leaves. Growth processes are influenced by temperatures which affect process rates: extreme temperatures may cause damage and disrupt growth temporarily or permanently (Landsberg, 2003). These processes and their interactions produce carbohydrates, some of which become wood - the product of interest to the commercial forester.

However, these processes can be affected by competition. Under these approaches, productivity is determined by the amount of light intercepted by the canopy, efficiency of 
light use proportion of assimilates allocated to wood and mortality losses (Cannell, 1989). Consequently, process-based modeling can be defined as a procedure by which the behavior of a system is derived from a set of functional components and their interactions with each other and the system environment, through physical and mechanistic processes occurring over time (Bossel, 1996). Even though, process-based models were originally designed for research purpose more recently they have been developed towards use in practical forest management (Fontes et al., 2010). Therefore, process-based models attempt to predict the products by describing the processes that lead to them, their responses to external driving variables and the interactions between them (Landsberg, 2003). This is observed on the schematic representation of the 3-PG process-based model (Fig.1).

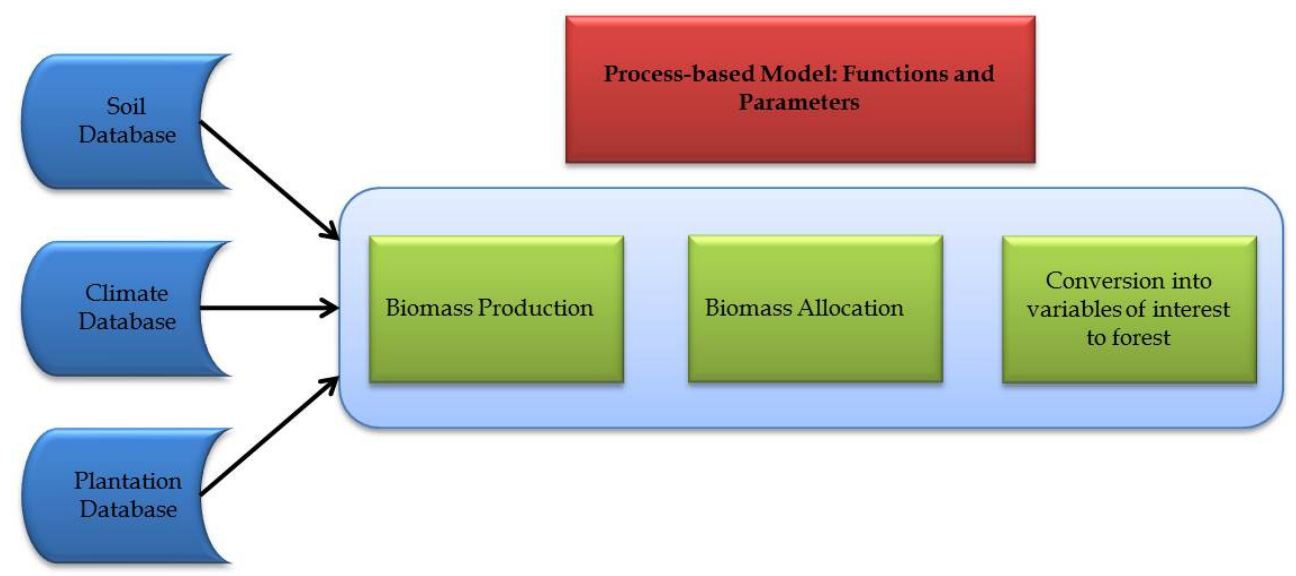

Figure 1. Schematic representation of 3-PG process-based model.

The 3-PG model is a stand-level model that uses monthly or annual time steps. It requires as inputs initial stand data, soil and weather data. The 3-PG model consists of five simple sub models: biomass production obtained from the assimilation of carbohydrates, the allocation of biomass between foliage, roots and stems, the determination of stem number, soil water balance, and the conversion of biomass values into variables of interest to forest managers.

In recent years, forest managers have expressed interest in the application of process-based models in management decision making (Mäkelä, 2000, Korzukhin et al., 1996, Johsen et al., 2001). Battaglia \& Sands (1997) have identified five potential uses of process-based forest productivity models as management tools: prediction of growth and yield, selection of new plantations sites, identification of site limitations on productivity, assessment of risk associated with locations or management options and use of models as surrogates for field experiments.

However, all these models share the problems of parameter estimation caused by lack of precise data and an incomplete understanding of some important processes. 


\subsection{Linking process-based and empirical forest model}

The term "hybrid modelling" refers to approaches that are grounded in both empirical and process-based concepts of forest dynamics, thus trying to capitalize on the advantages of each approach (Fontes et al., 2010). Specifically, the underlying idea is to benefit from the predictive ability and parsimony in the calibration data needs of empirical approaches as well as the explicit environment-dependence of process-based formulations (Fontes et al., 2010). This approach offers potentially the best prospects for developing models to support forest management (Battaglia et al., 1998).

The development of process-based models to predict forest growth has been developing rapidly in the last few years. However, operational applications in forest plantations are still at an early stage (Almeida et al., 2003). All these models cited in scientific literature share in common the need to assess and to evaluate various parameters and processes, modeled with sub-models, based on field measurements and independently calibrated (Sharpe \& Rykiel, 1991). Some sub-models, or a subset of sub-model parameters, will fail calibration because of the lack of adequate data, problems of scaling up, or poor understanding of processes (Mäkelä et al., 2000). In such case, and in order to predict system-level behavior (Mäkelä et al., 2000), these sub-models or sub-model parameters are best estimated by using empirical equations relating to the whole system (Sievänen \& Burk, 1993). Korzukhin et al. (1996) presented a detailed analysis of the relative merits of process-based models and empirical models, which highlighted the value of both classes of models and indicated how they can be applied in forest ecosystem management. The above considerations lead to the conclusion that the best option is to combine both types: empirical and process-based models in a joint and calibrated hybrid model.

Hybrid models were developed from complementary merging of well understood processes and reliable tree/stand empiricism, which aim to achieve a process model for the manager in which the shortcomings of both approaches can be overcome to some extent. There is a combination of causal (at the level of the process such as: carbon balance, water balance, soil carbon cycling, soil carbon cycling) and empirical (at the higher stand level the model is empirical) elements (Almeida et al., 2003).

Shifting views of the forest from primarily one as a production system for many products to an ecosystem with spatially and temporally complex interrelationships is changing the demand for information about the forest (Korzukhin et al., 1996). These new information needs are characterized by greater complexity, limited availability of mechanistic hypotheses, and paucity of data. In contrast to empirical models, process-based model seek primarily to describe data using key processes that determine an object's internal structure, rules, and behavior (Korzukhin et al., 1996). Both types of solutions can be developed across the full range of spatial scales. In Figure 2 we present the hybridized 3-PG model.

A hybrid approach combining the main advantages of process-based models and empirical models has been adopted in some cases. Baldwin et al. (1993) combined a single-tree empirical model called PTAEDA2 (Burkhart et al., 1987) with process-based model 
MAESTRO (Wang \& Jarvis, 1990). Using PTAEDA2 they projected to a certain age the stand variables used by MAESTRO to calculate biomass production, which was fed back to TAEDA2 to adjust its predictions. These steps were repeated to the end of rotation. In turn, Battaglia et al. (1999) used the process-based model PROMOD and the empirical model NITGRO developed for Eucalyptus nitens plantations. The model PROMOD predicted the mean annual increment (MAI; $\mathrm{m}^{3} \mathrm{ha}^{-1}$ year $^{-1}$ ) and estimated site index (SI) applying relationship MAI and SI. However, according to Johnsen et al. (2000) major constraints in the implementation of hybrid models for practical forestry are those related to soil and nutrient dynamics. The improvement of both process-based and empirical models will lead to better hybrid models. This architecture has been demonstrated to be successful as a practical tool in operational forestry (Almeida, et al., 2003).

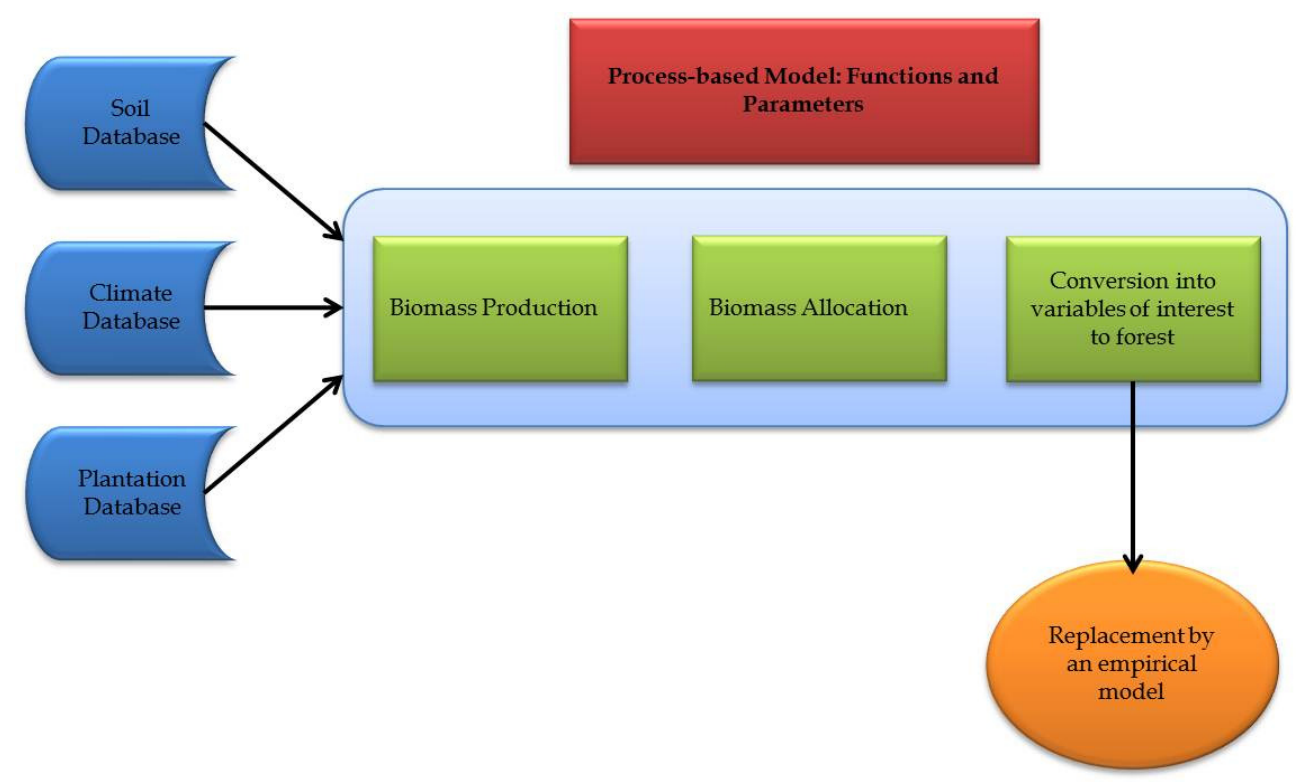

Figure 2. Schematic representation of 3-PG process-based mode hybridized (adapted from Fontes (2007)). In addition to Fig. 1, functions of replacement by an empirical model are added to the processbased model to get variables of interest to the forester.

\subsection{Overview of the 3-PG model hybridized}

The model called 3-PG (Physiological Principles Predicting Growth) is a process-based model that requires few parameter values and only readily available data inputs, and was developed by Landsberg \& Waring (1997) with the intent of being both simple and applicable to management.

The 3-PG model is based on physiological principles and parameterized with empirical data. It uses the concept of radiation use efficiency, where potential carbon gain is then constrained by the biology of the species and the physical characteristics of the site, and includes allometric 
relationship for carbon allocation. The 3-PG model is generalized, with monthly time-step, which means that biomass is the output. The important features of the model are that the output variables it produces are those of interest and utility to forest managers.

The 3-PG model lies between traditional growth and yield and detailed physiological representations, physiological process predicting growth, and the model is a "big leaf" carbon balance. A "big leaf" model is one that represents a forest canopy as a homogeneous structure, usually leaf area index (LAI), that is the area of leaves per unit area of ground surface. This model is based on two fundamentals ideas (Mason, 2010): net primary productivity is a linear function of absorbed photosynthetically active radiation ( $\varphi$ p.a.), with the slope of the function varying with environmental states and, allocation of carbon can be estimated from allometry and that allocation to roots will vary with fertility of soils. In addition, the 3-PG model uses Beer's law to estimate absorbed photosynthetically active radiation given any amount of radiation and LAI.

As described by Landsberg \& Waring (1997), the basic structure 3-PG model:

i. Estimates Gross Primary Production (PG) based on the utilizable photosynthetically active radiation ( $\varphi$ p.a.u) and the canopy quantum efficiency $(\alpha \mathrm{C})$. The value of $\varphi$ p.a.u is obtained by reducing the photosynthetically active radiation ( $\varphi$ p.a.) through nondimensional modifying factors whose values vary between 0 and 1 . The modifying coefficients reflect constraints imposed on the utilization of $\varphi$ p.a. by vapor pressure deficit (VPD), drought, and stand age. Soil fertility determines allocation of carbon to above and belowground components. Drought is defined for soils of different textures by the ratio of water in the root zone to the maximum available $(\theta)$. The model also includes suboptimal temperature and frost modifiers.

ii. Estimates Net Primary Production $\left(\mathrm{P}_{\mathrm{N}}\right)$ from PG. The model uses the proportion $\mathrm{PN} / \mathrm{PG}=\subset \mathrm{pp}$, which has been found to be $0.47 \pm 0.04$ for diverse types of forests and geographic locations (Waring, 2000).

iii. Estimates carbon in root biomass using two basic relations: the inverse relation between stem growth and the $\mathrm{P}_{\mathrm{N}}$ fraction allocated to soil, and the effects of drought and nutrition on the annual allocation of carbon to root biomass.

iv. Calculates changes in stand density over time using a sub-model derived from the selfthinning law coupled with stem growth rates.

v. Apportions carbon among aboveground tree components using allometric relations:

$$
\widehat{w} \mathrm{i}=\mathrm{a}_{\mathrm{i}} \widehat{w}^{\mathrm{Ni}}
$$

Where $\hat{\mathrm{w}}$ is the tree's total biomass and $\mathrm{i}$ is the tree component. The parameter $\mathrm{N}_{\mathrm{i}}$ reflects the species' genetic characteristics.

vi. The growth rate of trees declines with age. To this respect, the hydraulic limitations theory proposes that the decline of forest productivity with age is a consequence of whole-plant and leaf-specific hydraulic conductance with tree height caused by increased friction. Based on this theory, the 3-PG model estimates the effect of age on tree growth using the linear relation between hydraulic conductivity and $\mathrm{PN}$, in which stem conductance declines with age and thereby induces a lower stomatal conductance $\left(\mathrm{g}_{\mathrm{c}}\right)$. 


\section{Potential use of GIS coupled with process-based model for asses' forest productivity}

A review of forestry applications in GIS reveals an extensive range of activities. GIS for forest management may be characterized by two broad and related categories: resource inventory including monitoring and analysis, modeling or prediction to support decision making (McKendry \& Eastman, 1991).

The massive data management and its transformation into information requested by users with different goals of information, has been promoted heavily from the 80's with the rapid development of so-called Geographic Information Systems (GIS). System design involves the existence of a set of elements or parts that are interrelated, in the case of Geographic Information Systems the following elements can be distinguish: 1) User information, 2) Spatial and / or space, 3) Software for managing spatial data and 4) Hardware.

Unlike traditional information systems, GIS is a specialized system, designed to handle geographic data with spatial reference. Since human activity and the action of nature and their interactions occur in a geo-referenced environment (the earth), GIS provides a platform capable of structuring, integrating and connecting data of different nature, and enhancing the capabilities of analysis compared to Information Systems with no spatial reference.

A process-based model to estimate productivity in plantations, involves handling a wide range of spatially referenced data that needs to be collected from different sources, input to the GIS, standardized, organized, integrated and analyzed, generating new data for use as information in the process-based model that generates the results of growth and yield.

The data to be integrated corresponds to climate, soil, topography and plantations. Data should be organized into the GIS as a spatial data base model, creating subsystems that provide information to the process simulator.

The organization of a GIS system for this purpose is shown schematically in Figure 3.

The use of Geographic Information Systems, in our experience, demonstrated the high flexibility of analysis, data integration capabilities provided by GIS and functionality required for forest productivity studies. As shown in Figure 3, the concept of GIS used is modular and contains four subsystems described below.

\subsection{Data acquisition}

Corresponds to the use of input and storage facilities provided for the GIS software designed to input, store and edit basic data collected. This stage includes the standardization of information and the development of thematic maps and their associated databases.

The climate data include rainfall, temperatures (maximum, minimum and optimum for photosynthesis of the species), solar radiation, and vapor pressure deficit and frost days. In the case of soil chemical properties, N, P, K and trace elements were considered to construct 
a ranking of soil fertility. Soil physical properties were also used, such as depth, texture, structure, bulk density, field capacity and permanent wilting point allowed us to estimate available soil water holding capacity. Along with soil data details of geography and terrain such as latitude, longitude, slope, aspect, altitude and topographic position were also considered.

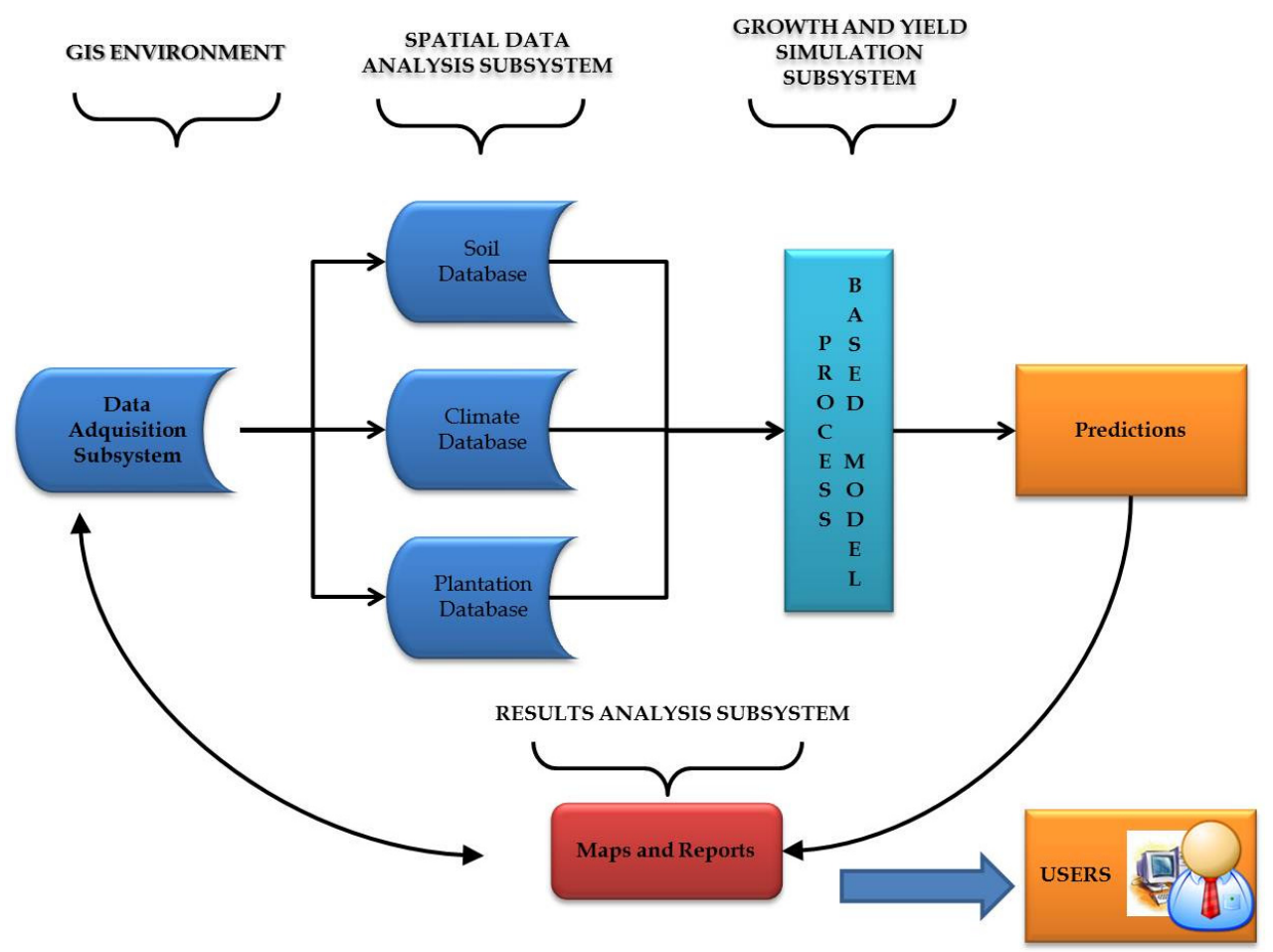

Figure 3. Diagram of the integration process and data analysis of GIS to quantify forest plantation productivity.

\subsection{Data integration and analysis}

This subsystem uses spatial analysis capabilities data to perform geospatial interpolation from discrete spatial data. As an example, the interpolation of climate can be mentioned where data from weather stations are interpolated to create surfaces with appropriate pixel size (pixel: unit of spatial resolution in the map). Soil and topography information were produced and integrated, using the GIS overlay capabilities that allow the integration of graphical data and their associated databases. Orographic description was made by the creation of Digital Terrain Models and their derived products: slope and aspect. Data from the forest and its spatial distribution were integrated to define areas with the specie and validate the response of the system. 


\subsection{Growth and yield simulator}

This subsystem corresponds to the software platform used to simulate forest development under different climate, soil and environmental conditions. This subsystem includes functions and species-specific physiological parameters that explain growth, such as specific leaf area, light conversion efficiency of photosynthesis, light conversion efficiency constraints on associated with temperature, fraction of absorbed radiation by the canopy, allometric equations, foliage turn-over, maximum leaf stomatal conductance, stomatal conductance canopy maximum and wood density. This subsystem produces for each geographic area productivity results for the species and forest site-specific conditions.

\subsection{Results and analysis subsystem}

The results may be returned to the GIS platform to be converted into thematic maps, editing and distribution to different information users.

\section{Application of 3-PG model and GIS to estimate productivity of Eucalyptus plantations in the region of Biobío, Chile}

To assess the appropriateness of a simplified process-based model to predict potential forest growth over the study area, we applied a geographic information system (GIS) with spatial layers of climate and soils to the 3-PG model.

\subsection{Study area}

The Biobío Region comprises $36,929 \mathrm{~km}^{2}$ extending north-south from $36^{\circ} 00^{\prime}$ to $38^{\circ} 30^{\prime}$ south latitude and east-west from $71^{\circ} 00^{\prime}$ west longitude to the Pacific Ocean. The Andes Mountains to the east and the Coastal Mountain Range to the west define four agro-climatic areas located longitudinally: the coastal dry sector, the inner dry sector, the central valley, and the Andean foothills. The climate and soils of each agro-climatic area determine potential land-uses and productive capacity (Del Pozo \& Del Canto, 1999).

\subsection{Functions and parameters of the model}

Considering the basic structure 3-PG model, Table 1 shows functions and parameters used in this study.

These functions and parameters differ from the original model (Landsberg \& Waring, 1997), following Sands (2000) for 10-year old Eucalyptus nitens. $\alpha \mathrm{C}$, canopy quantum efficiency, $\mathrm{MJ}^{-1}$;

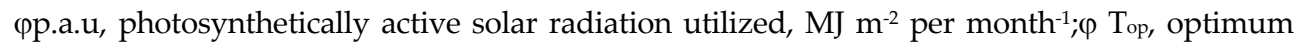
temperature for photosynthesis, ${ }^{\circ} \mathrm{C} ; \mathrm{Tmi}$, minimum temperature for growth, ${ }^{\circ} \mathrm{C} ; \mathrm{Tma}$, maximum temperature for growth, ${ }^{\circ} \mathrm{C} ; \mathrm{L}, \mathrm{LAI}, \mathrm{m}^{2} \mathrm{~m}^{-2}$; dia, average stem diameter $(\mathrm{mm}) ; \mathrm{m}$, soil fertility rank ( $m$ is 1 fertilized soil and decease to 0,1 in non-fertilized soils). To obtain maximum potential MAI, nutritional status was not limiting photosynthetic production and $\mathrm{m}$ is 1 . 


\begin{tabular}{|c|c|c|}
\hline Variable & $\begin{array}{l}\text { Values of functions and } \\
\text { parameters }\end{array}$ & References \\
\hline $\begin{array}{l}\text { Light conversion } \\
\text { efficiency of } \\
\text { photosynthesis }\end{array}$ & $\begin{array}{l}\text { Maximum } \alpha \mathrm{C} \text { ranges from } 1.8 \\
\text { to } 4.2 \mathrm{~g} \mathrm{C} \mathrm{MJ}^{-1} \text { pp.a.u }\end{array}$ & Landsberg, 1986; Waring, 2000 \\
\hline $\begin{array}{l}\text { Constraints on light } \\
\text { conversion efficiency } \\
\text { associated with } \\
\text { temperature }\end{array}$ & $\begin{array}{l}\text { Top was set at } 20^{\circ} \mathrm{C} \text {, Tmi } 2^{\circ} \mathrm{C} \\
\text { and Tma } 32^{\circ} \mathrm{C}\end{array}$ & Battaglia et al. (1998) \\
\hline Specific leaf area & $4.0 \mathrm{~m}^{2} \mathrm{~kg}^{-1}$ & Landsberg \& Waring (1997) \\
\hline $\begin{array}{l}\text { Fraction of radiation } \\
\text { absorbed by the canopy }\end{array}$ & $1-\left(1.38 \exp \left(-0,5^{*} \mathrm{~L}\right)\right.$ & Landsberg \& Waring (1997) \\
\hline $\begin{array}{l}\text { Allocation equation for } \\
\text { stem mass }\end{array}$ & $\begin{array}{l}\text { Stem mass, } \mathrm{kg}=0.00007^{*} \text { dia. } \\
\left(\mathrm{mm}^{2.65}\right)\end{array}$ & Tickle et al. (2001) \\
\hline $\begin{array}{l}\text { Allocation equation for } \\
\text { foliage mass }\end{array}$ & $\begin{array}{l}\text { Foliage mass, } \mathrm{kg}=0,00005^{*} \text { dia. } \\
\left(\mathrm{mm}^{2.65}\right)\end{array}$ & Tickle et al. (2001) \\
\hline Wood density & $500 \mathrm{~kg} \mathrm{~m}^{-3}$ & Sands (2000) \\
\hline Foliage turn-over & $2 \%$ per month ${ }^{-1}$ & Tickle et al. (2001) \\
\hline $\begin{array}{l}\text { Maximum leaf stomatal } \\
\text { conductance }\end{array}$ & $0.005 \mathrm{~m} \mathrm{~s}^{-1}$ & Sands (2000) \\
\hline $\begin{array}{l}\text { Maximum canopy } \\
\text { stomatal conductance }\end{array}$ & $0.02 \mathrm{~ms}^{-1}$ & Sands (2000) \\
\hline $\begin{array}{l}\text { Fraction of production } \\
\text { allocated to roots }\end{array}$ & $\begin{array}{l}\eta \mathrm{r}=\left(0,8^{*} 0,23\right) /(0,23+(0,8- \\
0,23) \text { m } \varphi \text { p.a.u }\end{array}$ & Sands (2000) \\
\hline
\end{tabular}

Table 1. Functional forms and parameters used in this study.

\subsection{Predicting potential productivity}

Battaglia et al. (1998) developed a simple analytic model for the relation between LAI and dry matter production in Eucalyptus nitens. In their model, "increasing LAI increased light interception and hence dry matter production, but simultaneously increased canopy respiration. Consequently, for a given light utilization coefficient, there was a value of LAI that maximized PN" (Battaglia et al. 1998). We ran the 3-PG model until reaching an optimum value of LAI, which we estimated using the equation of Battaglia et al. (1998) as:

$$
\mathrm{LAI}=1 / \mathrm{k} \ln \left[(\mathrm{s} \varepsilon \Omega \mathrm{k}) /\left(\mathrm{r}_{\mathrm{o}} \mathrm{NF}+\gamma\right)\right]
$$

Where LAI is the canopy leaf area index $\left(\mathrm{m}^{2} \mathrm{~m}^{-2}\right), \mathrm{k}$ is the canopy light extinction coefficient, $\mathrm{s}$ is the specific leaf area $\left(\mathrm{m}^{-2} \mathrm{~kg}^{-1} \mathrm{DM}\right), \varepsilon$ is the light utilization efficiency $\left(\mathrm{kg} \mathrm{C} \mathrm{MJ}^{-1}\right), \Omega$ is the annual incident radiation ( $\mathrm{MJ} \mathrm{m}^{-2} \mathrm{yr}^{-1}$ ), $\mathrm{r}_{0}$ is maintenance respiration rate per unit canopy $\mathrm{N}$ content $\left(\mathrm{kg} \mathrm{C} \mathrm{kg}^{-1} \mathrm{~N} \mathrm{yr}^{-1}\right), \mathrm{NF}$ is the average leaf $\mathrm{N}$ concentration $\left(\mathrm{kg} \mathrm{N} \mathrm{kg}^{-1} \mathrm{DM}\right)$ and $\gamma$ is rate of carbon loss as litterfall $\left(\mathrm{kg} \mathrm{C} \mathrm{kg}^{-1} \mathrm{DM} \mathrm{yr}^{-1}\right)$. We used the parameter values of Battaglia et al. (1998) with the exception of $\Omega$, which was measured in the Biobío region, and $\varepsilon$ which, as described below, we calculated on a site specific basis. 
Light utilization efficiency $(\varepsilon)$, therefore the optimal LAI, varies with site conditions, particularly water availability and temperature (Battaglia et al., 1998). To estimate how environmental conditions affect the distribution of optimal LAI throughout the Biobío Region, we used Landsberg's (1986) equation relating $\varepsilon$ to mean annual temperature $(\mathrm{T})$ and water stress index $(\mathrm{W})$, in the form:

$$
\varepsilon=0.00195 f_{\mathrm{W}} f_{\mathrm{T}}
$$

where $f \mathrm{~T}=\max \left\{0,\left(1-(\mathrm{T}-13.2 / 9.9)^{2}\right)\right\}$ and $f \mathrm{~T}=\max [0,(1+0.9 \ln W)]$

In this modeled relationship, $13.2{ }^{\circ} \mathrm{C}$ is a value that maximizes net canopy production and 9.9 is a value of temperature stress. $\mathrm{W}$ was calculated as the annual mean of the daily ratio of actual to potential evaporation (Battaglia et al., 1998). Actual evapotranspiration was calculated as the product of potential evaporation and a factor crop as estimated by Worledge et al. (1998). Potential evaporation was estimated from Mean Class A pan evaporation distributed in the Biobío region (Del Pozo \& Del Canto, 1999). Note that the LAI values estimated by the in $\mathrm{PN}$-maximizing model should not be interpreted as those necessarily present in the plantations.

\subsection{Analysis of plot information and validation of the 3-PG model}

To validate the 3-PG model for Eucalyptus nitens in the Biobío Region, data from 46 permanent, $1000 \mathrm{~m}^{2}$ plots were used. The plots were part of the national eucalypts growth and yield cooperative and were scattered over the main area of Eucalyptus nitens plantations in the Biobío region. The plots are measured annually and have between 6 and 12 measurements, at ages that vary between 7 and 17 years old. Data collected on each plot include age, diameter at breast height (Dbh), volume, and density together with climatic and soil variables that describe site conditions.

The accuracy of validation of the 3-PG model was evaluated by the Mean Square Error (MSE), in measured units and percentages. To evaluate bias the Aggregated Difference $(\mathrm{AD})$, in measured units and percent, was used.

\subsection{Geographic information system}

Equal productivity zones were delineated using GIS Software (Chang, 2004). The following databases were used:

\subsubsection{Spatial soil model}

The Earth Ordering System (scale 1:250,000) developed by Schlatter et al. (2004) and soil origin data provided by the Instituto de Investigaciones de Recursos Naturales (1964) were used to construct the soil layer. The maximum available soil water was estimated from retention curves provided by Carrasco et al. (1993). 


\subsubsection{Spatial climate model}

The spatial distribution of monthly maximum, mean and minimum temperatures was obtained from Santibáñez \& Uribe (1994). Estimates of monthly solar radiation values were derived from maximum and minimum data at direct measurements performed by the Instituto de Investigaciones Agropecuarias using the procedure of Bristow \& Campbell (1984). Maximum potential solar radiation on a flat surface was obtained by correcting from latitude and elevation (Running et al, 1987). This potential value was corrected by the monthly variation of the angle of solar declination over the earth's surface (Waring, 2000).

\subsubsection{Digital elevation model}

The slope and aspect models were derived from a digital terrain elevation model generated with information provided by regular Chilean cartography (Instituto Geográfico Militar, 2001). Slope and exposure classes were derived using a Triangle Irregular Network (TIN), which is an elevational data storage system (Crosier et al., 2004).

\subsubsection{Map construction}

Each digital coverage layer was created, cleaned and processed using the Arc Info WorkStation System version 7.1 running in a UNIX platform. GIS results were exported to the 3-PG model. Finally, the 3-PG estimations and the basic layers where converted to shape format and manipulated in Arc View 3.2, where the cartography was built. The resulting maximum MAI values were grouped using the legend tool to define potential productivity zones.

The classification method used is the Natural Breaks default classification method in Arc View. This method identifies breakpoints between classes using a statistical formula (Jenk's optimization). The Jenk's method minimizes the sum of the variance within each of the classes to find groupings and patterns inherent in the data (Crosier et al., 2004). We used the program 3PGpjs (Sands, 2000) to predict potential productivity with a 3-PG interface from the CSIRO Forestry and Forest Products \& CRC for Sustainable Production Forestry. The calibration of these models for diverse Eucalyptus species has been described by Landsberg et al. (2003).

\subsection{Results of the application}

To evaluate the effects of spatial variation in climate and soils on forest productivity across broad regions is of main importance to a forester. In our study, we are interested in predicting potential MAI, as measure of productivity, and how it is influenced by environmental factors.

\subsubsection{Model validation for MAI prediction}

MAI values observed in the growth plots varied between 23 and $50 \mathrm{~m}^{3} \mathrm{ha}^{-1}$ at age 10 and were highly correlated with MAI simulated by the 3-PG model. Additionally, a low bias was 
recorded with $\mathrm{AD}$ of 0.26 in absolute terms and $0.85 \%$ in percentage terms. The model also had acceptable precision; MSE had an absolute value of 4.55 and a percentage value of $14.6 \%$.

\subsubsection{Potential MAI in the Biobio region}

There are three main physiographic landscapes dominating the Biobío Region. The coastal range along to the Pacific Ocean and the Andes Cordillera enclose the Central Valley from north to south and create a great variety of climates, soils, and forest sites.

Predicted MAI classes for Eucalyptus nitens plantations ranged from $17 \mathrm{~m}^{3} \mathrm{ha}^{-1} \mathrm{yr}^{-1}$ to $62 \mathrm{~m}^{3}$ $\mathrm{ha}^{-1} \mathrm{yr}^{-1}$ in the Biobío Region general, predicted MAI increased in mountainous terrain in the foothills of the Andes following gradients in precipitation, annual temperature, and soil fertility (Fig. 4; Table 2). Not surprisingly, highest predicted MAI were in areas with highest precipitation, coolest annual temperatures, and the most fertile soils. Elevation by itself was not a good predictor of MAI, as highly productive sites occurred at both low and high elevations. Soil nitrogen concentrations on the most productive sites varied widely but on average, soils were considerably more fertile and held more water than sites with lower productivity (Table 2).

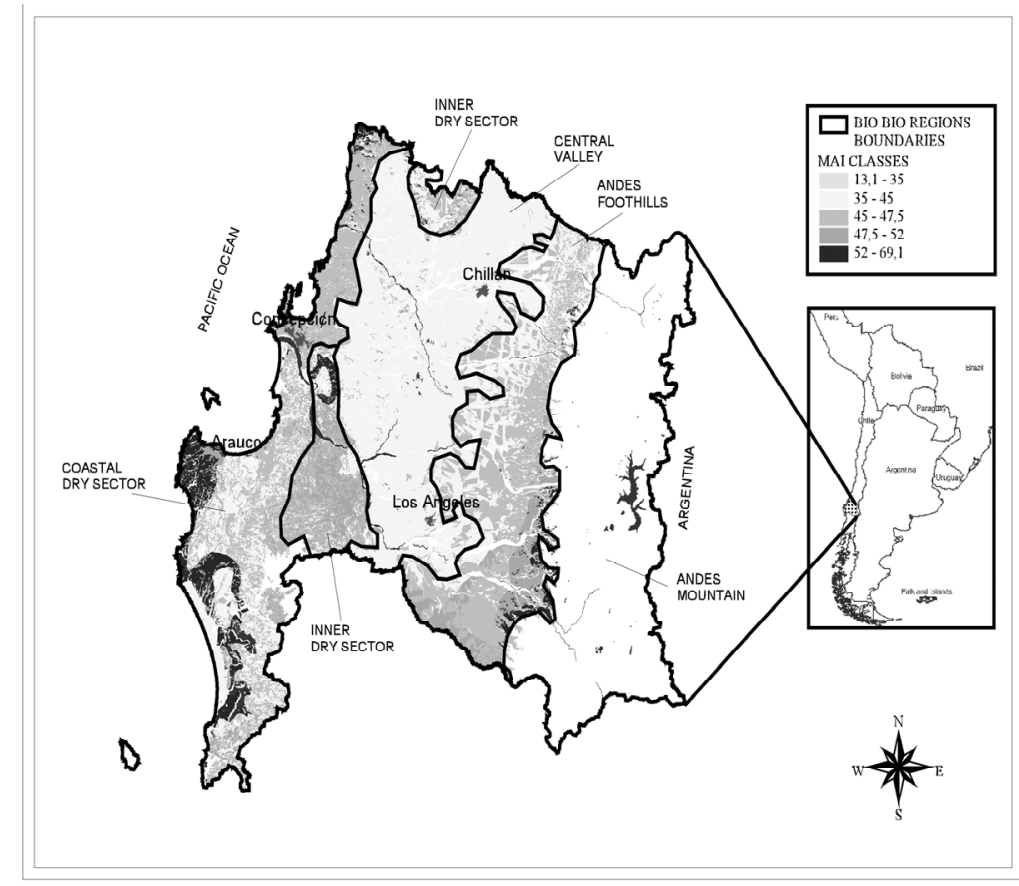

Figure 4. Potential productivity classes of $\mathrm{MAI}\left(\mathrm{m}^{3} \mathrm{ha}^{-1} \mathrm{yr}^{-1}\right)$ for the Biobío Region, as estimated by the 3-PG model. (The predicted values of MAI in each site are not possible to reach under the operational silviculture). 


\begin{tabular}{|c|c|c|c|c|c|c|}
\hline Site Class & \multicolumn{2}{|c|}{$\begin{array}{c}\text { MAI } \\
\left(\mathrm{m}^{3} \mathrm{ha}^{-1} \mathrm{yr}^{-1}\right)\end{array}$} & $\begin{array}{c}\Omega \\
\left(\mathrm{MJ} \mathrm{m} \mathrm{m}^{-2} \mathrm{yr}^{-1}\right)\end{array}$ & \multicolumn{2}{|l|}{$\begin{array}{c}\mathrm{P} \\
\left(\mathrm{mm} \mathrm{yr}^{-1}\right)\end{array}$} & $\begin{array}{c}\mathrm{T} \\
\left({ }^{\circ} \mathrm{C}\right)\end{array}$ \\
\hline Very high & \multicolumn{2}{|c|}{$>55$} & 5.5 & \multicolumn{2}{|l|}{$1250-2000$} & 13.0 \\
\hline Very high & \multicolumn{2}{|c|}{$>55$} & 6.2 & \multicolumn{2}{|l|}{$1500-2550$} & 12.0 \\
\hline Moderate & \multicolumn{2}{|c|}{$47.6-52.0$} & 5.8 & \multicolumn{2}{|l|}{$640-1100$} & 14.7 \\
\hline Very low & \multicolumn{2}{|c|}{$>35$} & 6.6 & \multicolumn{2}{|l|}{$750-1250$} & 14.0 \\
\hline \multicolumn{7}{|c|}{ (a) } \\
\hline Site Class & $\begin{array}{c}\text { MAI } \\
\left(\mathrm{m}^{3} \mathrm{ha}^{-1} \mathrm{yr}^{-1}\right)\end{array}$ & Soil order & $\begin{array}{l}\text { Altitude } \\
\text { (m) }\end{array}$ & Texture & $\begin{array}{l}\text { WHC } \\
(\mathrm{mm})\end{array}$ & $\begin{array}{l}\mathrm{N} \\
(\%)\end{array}$ \\
\hline Very high & $>55$ & Alfisol & 160 & Fr-arc & 410 & $0.05-0.25$ \\
\hline Very high & $>55$ & Inceptisol & 830 & Fr-lim & 570 & $0.18-0.35$ \\
\hline Moderate & $47.6-52.0$ & Alfisol & 130 & Fr-arc-are & 340 & 0.04-0.09 \\
\hline Very low & $>35$ & Alfisol & 170 & Are & 52 & $0.01-0.07$ \\
\hline
\end{tabular}

(b)

Note: In table 2a) and 2b), MAI is the potential mean annual increment as estimated by 3-PG model; $\mathrm{N}$ is soil nitrogen; WHC is available soil water holding capacity; $\Omega$ is the annual incident radiation; $P$ is the annual precipitation, and $T$ is the mean annual temperature. Data were provided by the Instituto de Investigaciones de Recursos Naturales (1964) and Instituto de Investigaciones Agropecuarias (Del Pozo \& Del Canto, 1999).

Table 2. a) Climates variables related to the potential productivity of 10-yeard old Eucalyptus nitens on the Biobío Region; b) Soil variables related to the potential productivity of 10-yeard old Eucalyptus nitens on the Biobío Region.

Combined with spatial information derived from GIS, the 3-PG model can generate valuable information for the development of operational silviculture (Almeida et al., 2004). The AD values $(0.85 \%)$ and MSE values (14.6\%) obtained for MAI confirm that process-based models hybridized have precision levels similar to traditional inventories. Our work corroborates the suggestion of Tickle et al. (2001) that process-based models are a valuable tool for predicting growth at a regional level. Additionally, 3-PG model provide insights into the role of environmental variables in determining MAI that are very difficult to obtain with traditional inventories (Waring, 2000; Almeida et al., 2004).

To better understand the factors that explain potential productivity of Eucalyptus nitens plantations in the Biobío region, we used soil and climate information from Del Pozo \& Del Canto (1999) and Carrasco (1993). In addition typical values of observed environmental variables are presented for very high, moderate and very low MAI classes (Table 2a and 2b).

Highest productivity sites occur on inceptisols and on those alfisols in areas with relatively high precipitation and regularly subjected to freezing temperatures. In the Biobío Region, 
inceptisols are derived from volcanic ash, and have high water holding capacity, good drainage, and high nitrogen concentrations (Rodríguez et al., 2009). They also occur in areas of relatively high precipitation. Alfisols are marine terrace soils with good drainage. In addition to high precipitation, those alfisols with high productivity also have high water holding capacity, with relatively high average soil nitrogen concentrations (Table 2). High productivity areas span a wide range of elevation, mean annual temperature, and annual incident radiation. Consequently, the productivity of Eucalyptus nitens in the Biobío Region does not respond directly to any of these three factors (Rodríguez et al., 2009). However, the factors considered here may affect productivity through several distinct mechanisms, in which factors can interact or factors are related with seasonal variation (Battaglia \& Sands, 1997). Because water is considered to be the main factor limiting productivity, productivity is consistently related to the capacity of the soil to store water (Dye et al., 2004); this is the case with the inceptisols derived from volcanic ash and alfisols derived from marine terraces, that have high water holding capacity and can explain the highest productivity in these sites (Table 2).

The relatively small change in MAI over a large elevational span is consistent with the ecophysiology of Eucalyptus nitens. Optimal temperatures for photosynthesis span between a wide range $\left(14\right.$ to $20^{\circ} \mathrm{C}$ ) for the species (Battaglia et al. 1996) - this commonly occurs with temperatures in the study area. Our results support the hypothesis of Battaglia et al. (1996) that the broad photosynthetic response of Eucalyptus nitens enables it to acclimate to a wider range of environments than many other Eucalyptus species. Eucalyptus nitens in the Biobío Region occurs in elevations from 0 and 830 m.a.s.l, with temperatures varying between 8 and $32^{\circ} \mathrm{C}$ in the summer and -3.0 to $13^{\circ} \mathrm{C}$ in winter; the higher elevations experience frequent winter frosts. Similar to the results of Battaglia et al. (1998) for Eucalyptus nitens in Australia, frost has little or no effect on this species' MAI in Chile.

Moderate levels of MAI were predicted for the Coastal Range. The soils of Coastal Range are derived from granitic and metamorphic rocks that compose the so-called "Batholitic Coastal", and have been seriously impacted by erosion. MAI values for the Coastal Range were lowest in the north and highest in the south following a gradient of precipitation and plant-available soil water holding capacity (Table 2). Lowest growth rates occurred in Central Valley at middle elevations with decreasing precipitation, high evapotranspiration rates, and a long drought period (approximately six months). The sandy soils of the Central Valley also have low inherent fertility and very low water holding capacity (Fig. 4; Table 2).

The very low productivities occurred in sandy soils derived from metamorphic and granitic rocks. These soils have low water retention capacity. The very low productivity sites were in Central Valley on entisols; these are young soils originating in the Biobío area from various rock types (e.g. granitic, metamorphic, andesitic, and basaltic). They are sandy soils with excessive drainage, low soil water holding capacity (less than $52 \mathrm{~m}^{3} \mathrm{ha}^{-1}$ of available water), and low nitrogen concentrations. Compounding the low water holding capacity of soils, 
these areas also have low annual precipitation $(750$ to $1000 \mathrm{~mm})$ and high solar radiation potentials (> $6.5 \mathrm{MJ} \mathrm{m}^{2} \mathrm{yr}^{-1}$ ), which would increase evaporative demand (Table 2). These factors suggest that productivity in these areas is strongly controlled by water holding capacity and perhaps nitrogen limitations. Battaglia et al. (1998) found that LAI of Eucalyptus nitens plantations in Australia increased sharply as annual mean temperature increased from 7 to 11 degrees $C$ and reached a plateau between 13 and to 14 degrees (the highest temperature measured for Eucalyptus nitens). We found a similar pattern; however, the LAI of Eucalyptus nitens plantations in the Biobío Region plateaus reach lower temperatures than those present in Australia. However, although mean annual temperature had a strong influence of LAI in our study, productivity was influenced more strongly by the constraints on leaf efficiency exerted by water availability and soil fertility (for more details see Rodríguez et al., 2009).

This finding is consistent with the hypothesis of Ollinger et al. (1998) and Coops et al. (2001) that forest productivity is strongly correlated with precipitation and suggests that water is an important factor controlling regional pattern of productivity in forest types, as well as in Eucalyptus nitens, which was demonstrated in our study. Additionally Eucalyptus nitens was very sensitive to water soil availability (Fig. 4) in areas with low water holding capacity of soils. These findings are consistent with the hypothesis of White et al. (2000) that water stress reduces dramatically the growth rate of Eucalyptus nitens due to the decrease of the osmotic potential and bulk elastic modulus in response to water stress.

Understanding how productivity varies across complex environmental gradients requires modeling that combines influences of radiation, temperature, humidity deficits, and drought and soil fertility as they change spatially and temporally.

\section{Conclusion}

In our work, we linked process-based and empirical forest model with GIS to asses' site quality for Eucalyptus nitens en the Biobío region, Chile. We defined GIS system as modular and contain four subsystems: Data acquisition, Data integration and analysis, Growth and yield simulator and Results and Analysis subsystem. The 3-PG model with GIS showed the usefulness for managing spatial data and analyzing temporal trends, and provided regional estimates of forest productivity.

Combined with spatial information derived from GIS, the 3-PG hybridized model can generate valuable information for the development of operational silviculture, and measure of forest productivity as MAI can be derived in a GIS from readily-available topographic data, climate data and soils map. A process-based model coupled with GIS showed potential to serve as a useful tool to screen areas as prospective plantations sites.

Our results in the Biobío region indicate that annual precipitation; available soil water holding capacity and low levels of soil nitrogen are the principal factors influencing 
Eucalyptus nitens productivity. Our analysis was able to separate the effects of limiting water from those of nutrients, and it is reasonable to conclude that soil water availability is an important factor controlling regional patterns of productivity. Highest productivity sites occur in areas with relatively high precipitation and regularly subjected to freezing temperatures in Eucalyptus nitens.

In our study Eucalyptus nitens reduced growth dramatically in areas with low water holding capacity of soils. Additionally, we found that large changes in elevation have only a small influence of the productivity of Eucalyptus nitens in the Biobío Region. Consequently, it is reasonable to conclude that soil water availability is an important factor controlling regional patterns of productivity as has been demonstrated in similar studies.

\section{Author details}

Rolando Rodríguez and Pedro Real

Forest Science Faculty, Universidad de Concepción, Chile

\section{References}

Almeida, A.C.; Maestri, R.; Landsberg, J.J. \& Scolforo, J.R.S. (2003). Linking processbased models and empirical forest model in Eucalyptus plantations in Brazil. In: Modeling Forest System, Ana Amaro et al. (Eds.), CABI Publishing. ISBN 0-85.199693-0.

Almeida, A.C.; Landsberg, J.J.; Sands, P.J.; Ambrogi, M.S.; Fonseca, S.; Barddal, S.M. \& Bertolucci, F.L. (2004). Needs and opportunities for using a process-based productivity model as a practical tool in Eucalyptus plantations, Forest Ecology and Management, Vol. 193, pp 67-177.

Baldwin, V.C.; Burkhart, H.E.; Dougherty, P.M. \& Teskey, R.O. (1993). Using a growth and yield model (PTAEDA2) as a driver for a biological model (MAESTRO). US Department of Agricultural, Forest Service, Southern Forest Experimental Station, New Orleans, Research Paper SO-276, 9 pp.

Battaglia, M.; Beadle, C. \&. Loughead, S. (1996). Photosynthetic temperature responses of Eucalyptus globulus and Eucalyptus nitens, Tree Physiology, Vol. 16, pp 81-89.

Battaglia, M. \& Sands, P. (1997). Modeling site productivity of Eucalyptus globulus in response to climate and site factors, Australian Journal of Plant Physiology, Vol. 24, pp 831-850.

Battaglia, M.; Cherry, M.L.; Beadle, C.L.; Sands, P.J. \& Hingston, A. (1998). Prediction of leaf area index in eucalypt plantations: Effects of water stress and temperature, Tree Physiology, Vol. 18, pp 521-528.

Battaglia, M.; Sands, P.J. \& Candy, S.G. (1999). Hybrid growth model to predict height and volume growth in young Eucalyptus, Forest Ecology and Management, Vol. 120, 193201. 
Bernier, P., Landsberg, J.; Raulier, F; Almeida, A.; Coops, N.; Dye, P.; Espinosa, M.; Waring, R.\& Whitehead, D. (2003). Using process-based models to estimate forest productivity for management purposes. In: XII World Forestry Congress. Available at: http://www.fao.org/DICREP/ARTICLE/WFC/01515-B4.htm.

Bossel, H. (1996). TREEDYN3 Forest Simulation Model, Ecological Modelling, Vol. 90, pp 187-227.

Bristow, K.L. \& Campbell, G.S. (1984). On the relationship between incoming solar radiation and daily maximum and minimum temperature. Agricultural and Forest Meteorology, Vol. 32, pp 159-166.

Burkhart, H.E.; Farrar, L.R.; Amateis, R.L. \& Daniels, R.F. (1987). Simulation of individual tree growth and stand development in loblolly pine plantations on Cutover, site prepared areas, Virginia Polytechnic Institute and State University, School of Forestry and Wild Life Resources, Blacksburg, FWS 1-87, 47 pp.

Cannel, M.G.R. (1989). Physiological basis of wood production: a review. Scandinavian Journal of Forest Research, Vol. 4, pp 459-490.

Carrasco, P.; Millán, J. \& Peña, L. (1993). Suelos de la cuenca del río Bío Bío, características y problemas de uso. In: Gestión de los Recursos Hídricos de la Cuenca del Río Bío Bío y del Area Marina Costera Adyacente, F. Faranda \& O. Parra (Eds), Universidad de Concepción, 12-108 pp (in Spanish).

Chang, K. (2004). Introduction to geographic information system, McGraw Hill, New York.

Constable, J.V. \& Friend, A.L. (2000). Suitability of process-based tree growth models for addressing tree response to climate change, Environmental Pollution, Vol. 110, pp 4759.

Coops, N.C. \& Waring, R.H. (2001). Estimating forest productivity in the eastern Siskiyou Mountain of southern Oregon using satellite-derived process-based model, 3 PGS, Canadian Journal of Forest Research, Vol. 311, pp 143-154.

Crosier, S.; Booth, B.; Dalton, K.; Mitchell, A. \& Clark, K. (2004). ARGIS 9 Getting started with ARCGIS, ESRI Pr, ISBN: 9781589480919.

Daniel, T.W.; Helms, J.A. \& F.S. Baker. (1979). Principles of silviculture, McGraw-Hill Company, New York.

Del Pozo, A. \& Del Canto, S. (1999). Áreas agroclimáticas y sistemas productivos en la VII y VIII Regiones, Ministerio de Agricultura, Chillán, 115 pp. (in Spanish).

Dye, P.J.; Jacobs, S. \& Drew, D. 2004. Verification of 3-PG growth and water-use predictions in twelve Eucalyptus plantations stands in Zululand, South Africa, Forest Ecology and Management, Vol. 193, pp 197-218.

Fontes, L. (2007). Process-based and hybrid forest models. Available at http://www.efi.int/attachments/luis_pontes-presentation/PDF.

Fontes, L.; Bontemps, J-D.; Bugmann, H.; Van Oijen, M.; Gracia, C.; Kramer, K.; Lindner, M.; Rötzer, T. \& Skovsgaard, J.P. (2010). Models for supporting forest management in a changing environments, Forest System, Vol. 19, pp 8-29. ISSN: 1131-7965. 
Hari, P.; Nikinmaa, E. \& Korpilathti, E. (1991). Modelling: canopy, photosynthesis, and growth. In: Physiology of Trees, Ed. A.S. Raghavondra, John Wiley and Sons, New York.

Instituto de Investigaciones de Recursos Naturales. (1964). Suelos. Descripciones Proyecto Aerofotogramétrico Chile/O.E.A./B.I.D. Publicación N². Santiago, Chile. (in Spanish).

Instituto Geográfico Militar. (2001). Colección Geografía de Chile. IGM. Santiago, Chile. (in Spanish).

Johnsen, K.; Samuelson, L.; Teskey, R.; Mc Nulty, S. \& Fox, T. (2001). Process models as tools in forestry research and management, Forest Science, Vol. 47 No. 1, pp 2-8.

Kirk, R. W. \& Burk, T.E. (2004). Regional-scale forest production modeling using processbased models and GIS. In: Proceedings of the 4th Southern Forestry and Natural Resources GIS Conference, 68-88 pp. Available at http://facstaff.elon.edu/rkirk2/files/rkirk_cv.pdf.

Korzukhin, M.D., Ter-Mikaelian, M.T. \& Wagner, R.G. (1996). Process versus empirical models: which approach for forest ecosystem management, Canadian Journal of Forest Research, Vol. 26, pp 879-887.

Landsberg, J.J. (1986). Physiological ecology of forest production, Academic Press, London.

Landsberg, J.J. (2003). Modelling forest ecosystems: state-of-the-art, challenges and future directions, Canadian Journal of Forest Research, Vol. 33, pp 385-397.

Landsberg, J. J.; Waring, R.H. \& Coops, N.C. (2003). Performance of the forest productivity model 3-PG applied to a wide range of forest types, Forest Ecology and Management, Vol. 172, pp 199-214.

Landsberg, J.J. \& Gower, S.T. (1997). Applications of physiological ecology to forest management, Academic Press, San Diego.

Landsberg, J.J. \& Waring, R.H. (1997). A generalized model of forest productivity using simplified concepts of radiation-use efficiency, carbon balance, and partitioning, Forest Ecology and Management, Vol. 95, 209-228.

Mäkelä, A., Landsberg, J.J.; Ek, A.R.; Burk., T.E.; Ter-Mikaelian, M.; Agren, G.I.; Oliver, C.D. \& Puttonen, P. (2000). Process-based model for forest ecosystem management: current state of the art and challenges for practical implementations, Tree Physiology, Vol. 20, No 5-6, pp 289-298.

McKendry, J.E. \& Eastman, J.R. (1991). Applications of GIS in Forestry: A review. Available at www.nrac.wvu.edu/classes/for326/GISInForestryReviewPaper.pdf.

Mason, E.G. (2010). Growth and yield modeling in New Zealand. In: Forest Growth \& Yield Hybrid Modeling, Cristian Higueras (Ed.), University of Concepción Press.

Medlyn, B.; Duursma, R.A. \& Zeppel, M.J.B. (2011). Forest productivity under climate change: a checklist for evaluating model studies, Climate Change, Vol. 2, pp 332-355. 
Ollinger, S.V.; Aber, J.D. \& Federer, C.A. (1998). Estimating regional productivity and water yield using model linking to a GIS, Landscape Ecology, Vol. 13, pp 323334.

Pinjuv, G.L. (2006). Hybrid forest modelling of Pinua radiata D. Don in Canterbury, New Zealand. Thesis submitted fulfillment of the requirement for the Degree of Doctor of Philosophy in Forestry, University of Canterbury, New Zealand.

Rodríguez, R; Real, P.; Espinosa, M.A. \& Perry, D.A. (2009). A process-based model to evaluate site quality for Eucalyptus nitens in the Bio-Bio Region of Chile, Journal of Forestry, Vol. 82, No 2, pp 149-162.

Runing, S.W., Nemani, R.R. \& Hungenford, R.D. (1987). Extrapolation of synoptic meteorological data in mountain terrain and its use for simulating forest evapotranspiration and photosynthesis. Canadian Journal of Forest Research,Vol. 17, pp 472-483.

Sands, P. 2000. 3PGpjs -a user-friendly interface to 3-PG, the Landsberg and Waring model of forest productivity, Cooperative Research Centre for Sustainable Production Forestry and CSIRO Forestry and Forest Products, Technical Report 29, Tasmania, 16 pp.

Santibáñez, F. \& Uribe, C.J. (1993). Cartas del mapa agroclimático de Chile, Universidad de Chile. Facultad de Ciencias Agrarias y Forestales, 99 pp. (in Spanish).

Sharpe, P.J.H. \& Rykiel, E.J. (1991). Modelling integrated response of plants to multiple stresses. In: Response of Plants to Multiple Stresses, H.A. Mooney et al. (Eds.), Academic Press, New York.

Schlatter, J.E. (2004). Sistema de ordenamiento de la tierra: Herramienta para la planificación forestal aplicada a las regiones VII, VIII y IX, Universidad Austral de Chile, Serie Técnica, 114 pp. (in Spanish).

Shindler, B. (1998). Landscape-Level Management: It's All About Context, Journal of Forestry, Vol. 98, pp 10-14.

Sievänen, R. \& Burk, T.E. (1993). Adjusting a process-based model for the dimensional growth model for varying site conditions through parameter estimation, Canadian Journal of Forest Research, Vol. 23, pp 1837-1851.

Tickle, P.K., Coops, N.C. \& Hafnes, S.D. (2001). Comparison of a forest model (3-PG) with growth and yield models to predict productivity at Bago State Forest, NSW, Australian Forestry, Vol. 64, pp 111-122.

Vanclay, J. (1994). Modelling forest growth and yield: Applications to mixed tropical forests, Cab International, ISBN 0851989136.

Wang Y. P., \& Jarvis P. G. 1990. Description and validation of an array model-MAESTRO, Agricultural and Forest Meteorology, Vol. 5, pp 257-280.

Waring, R. H. (2000). A process model analysis of environmental limitations on the growth of sitka spruce plantations in Great Britain, Forestry, Vol. 73, pp 65-79.

White, J.D., Coops, N.C. \& Scott, N.A. (2000). Estimates of New Zealand forest and shrub biomass from the 3-PG model, Ecological Modelling, Vol. 131, pp 175-190. 
Worledge, D.; Honeysen, J.L.; White, D.A.; Beadle, C.D. \& Hetherington, S.J. (1998). Scheduling irrigations in plantations of Eucalyptus globulus and Eucalyptus nitens: A practical Guide, Tasforest, Vol. 10, pp 91-101. 